\title{
“PANDO” LIVES: MOLECULAR GENETIC EVIDENCE OF A GIANT ASPEN CLONE IN CENTRAL UTAH
}

\author{
Jennifer DeWoody ${ }^{1,3}$, Carol A. Rowe ${ }^{2}$, Valerie D. Hipkins ${ }^{1}$, and Karen E. Mock ${ }^{2}$
}

\begin{abstract}
Aвstract.-While clones of trembling aspen (Populus tremuloides, Michx.) in the Intermountain West of North America are expected to be large, one putative genet in central Utah, identified from morphological evidence, has garnered particular attention for its size, even gaining the nickname "Pando" (Latin for "I spread"). In order to determine if a single genetic individual coincides with the morphological boundary of "Pando," we sampled 209 stems on a 50-m grid throughout the putative clone for analysis at 7 microsatellite loci. We have identified a single genetic entity concurrent with that described from morphological characteristics. Spatial analyses indicate that the clone covers approximately 43.6 ha. Surprisingly, an additional 40 genotypes were identified adjacent to the putative clone, indicating that genet diversity may be high in the stand as a whole. In confirming the existence of the "Pando" clone, we suggest that this organism will provide valuable opportunities to study important biological processes such as clonal growth, somatic mutation, and senescence.
\end{abstract}

Key words: aspen, clone, microsatellite.

Trembling aspen (Populus tremuloides, Michx.) is the most widely distributed tree in North America (Little 1971) and is noted for its ability to reproduce vegetatively via root suckers, resulting in genetically identical stems, or ramets, occurring within stands. Sexual reproduction, by contrast, is putatively rare and episodic in western landscapes, as seedlings require a narrow, ephemeral range of conditions to become established (Kemperman and Barnes 1976, Romme 1982, Romme and Despain 1989).

The size of single genetic individuals (genets) resulting from repeated suckering varies across the species range. Studies of aspen in eastern North America indicate that stand and genet size tend to be small, $<1$ ha to a few hectares (Barnes 1966, Kemperman and Barnes 1976, Wyman et al. 2003). Recent studies of aspen in the Pacific West (Cascade and Sierra Nevada Mountains) indicate that while stand size can be large ( $\leq 141$ ha; Di Orio et al. 2005), genet size tends to remain small, with large stands being composed of multiple genetic individuals (Hipkins and Kitzmiller 2004). Aspens in the Intermountain West have gained the most attention because of their large stand sizes and clone sizes, as indicated by morphological studies (Barnes 1966, Kemperman and Barnes 1976, Mitton and Grant 1996).

The putative clone referred to as "Pando," first described from aerial-photograph analysis, is estimated to cover over 40 ha and contain around 47,000 stems (Kemperman and Barnes 1976). Subsequent reports nominating the predicted clone as the world's largest organism were based on Kemperman and Barnes' morphological study but did not include molecular genetic evidence (Grant et al. 1992, Grant 1993). Here we used putatively neutral molecular markers (microsatellites) to determine whether the phenotypic boundary defined as Pando (Kemperman and Barnes 1976) corresponds to a single multilocus molecular genotype (genet) or to multiple distinct genets.

\section{Methods}

To delineate the clone described as "Pando," samples were collected from 209 stems defined by a $50-\mathrm{m}$ grid within and adjacent to the boundary described by Kemperman and Barnes (1976). The site is located on Fishlake National Forest $\left(38^{\circ} 31^{\prime} \mathrm{N}, 111^{\circ} 45^{\prime} \mathrm{W}\right)$ in central Utah (Fig. 1). Leaf samples, or cambium samples where canopy height prevented leaf collection

\footnotetext{
${ }^{1}$ USDA Forest Service, PSW Research Station, National Forest Genetics Lab, 2480 Carson Road, Placerville, CA 95667.

${ }^{2}$ Department of Wildland Resources, Utah State University, Logan, UT 84322-5230.

${ }^{3}$ Present address: University of Southampton, School of Biological Sciences, Building 62, Boldrewood Campus, Southampton SO16 7PX, United Kingdom. E-mail: j.dewoody@soton.ac.uk
} 


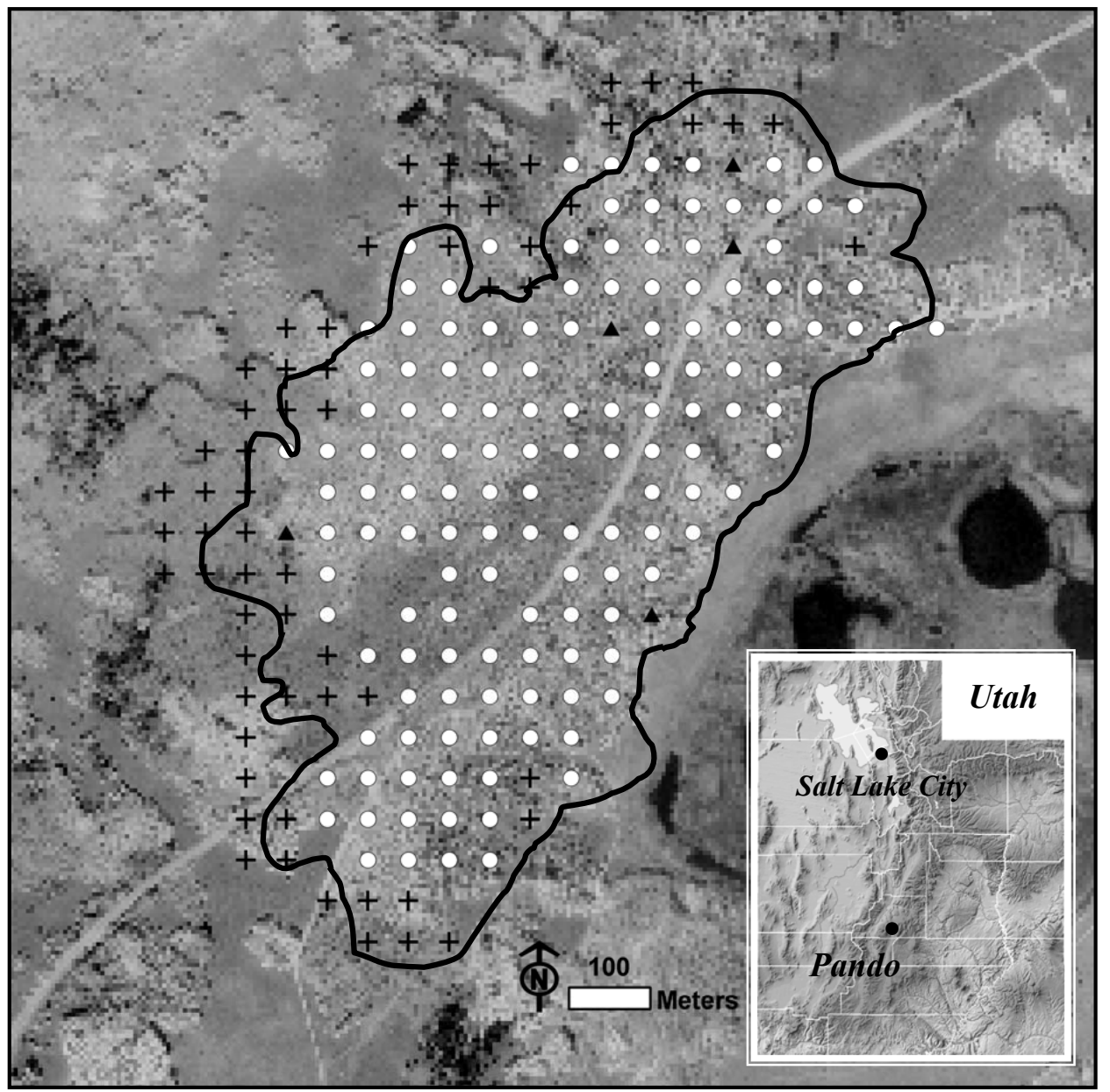

Fig. 1. "Pando," the massive aspen clone located in central Utah. The boundary is from Kemperman and Barnes (1976). Points indicate sampled stems located on a 50-m grid. Circles indicate stems sharing the dominant "Pando" genotype. Triangles indicate genets differing from the dominant genotype at a single allele. Crosses indicate stems differing at $\geq 4$ alleles. Gaps on the sampling grid within the black boundary represent places that lacked a stem within a 5$\mathrm{m}$ radius of the grid point. The dark area in the center of the stand north of the road resulted from an exclosed treatment that successfully stimulated vegetative reproduction.

(19\% of stems), were taken from canopy trees located within a 5-m radius of the grid coordinates (23 points lacked samples). Tissue was preserved in silica and transported to Utah State University (USU) in Logan, Utah, or to the National Forest Genetics Lab (NFGEL) in Placerville, California. Samples were collected in July 2006. Samples were equally divided between these laboratories in a spatially alternating pattern.

Following manufacturer's instructions, we isolated total genomic DNA from $30 \mathrm{mg}$ of tissue using the Qiagen ${ }^{\circledR}$ DNEasy-96 Plant Protocol for fresh tissue. Samples were assayed for 7 microsatellite loci (available from van der Schoot et al. 2000 and from http://www.ornl .gov/sci/ipgc/ssr_resource.htm): GCPM_970-1, PMGC-433, PMGC-576, PMGC-2571, WPMS14, WPMS-15, and WPMS-20. Microsatellites were amplified in a $10.0-\mu \mathrm{L}$ total reaction volume containing 5 ng template DNA, $1 \mathrm{X}$ reaction buffer (supplied with enzyme), 1.8-2.0 $\mathrm{mM} \mathrm{MgCl}, 200-250 \mu \mathrm{M}$ each dNTP, 0.25-0.4 $\mu \mathrm{M}$ each of the forward and reverse primers, and $0.2-0.3$ units Taq polymerase. At the NFGEL, reactions were carried out using a touchdown program (S. DiFazio personal communication): $95^{\circ} \mathrm{C}$ for 15:00 (mm:ss), 4 cycles 
of $94{ }^{\circ} \mathrm{C}(00: 30), 55{ }^{\circ} \mathrm{C}(00: 30), 72{ }^{\circ} \mathrm{C}(01: 00) ; 4$ cycles of $94{ }^{\circ} \mathrm{C}(00: 30), 52{ }^{\circ} \mathrm{C}(00: 30), 72{ }^{\circ} \mathrm{C}$ (01:00); 25 cycles of $94{ }^{\circ} \mathrm{C}(00: 30), 50{ }^{\circ} \mathrm{C}$ (00:30), $72{ }^{\circ} \mathrm{C}(01: 00)$; and a final extension of $72{ }^{\circ} \mathrm{C}$ for 15:00. The reaction conditions for PMGC-2571, WPMS-14, WPMS-15, and WPMS-20 were modified to raise the annealing temperature to $58^{\circ} \mathrm{C}$ for the first 4 cycles. At the USU laboratory, thermocycling conditions were as follows: $95{ }^{\circ} \mathrm{C}(02: 00)$ followed by 30 cycles of $94^{\circ} \mathrm{C}(00: 30), 52-59^{\circ} \mathrm{C}(00: 40)$, $72{ }^{\circ} \mathrm{C}(00: 50)$, followed by a final extension at $72{ }^{\circ} \mathrm{C}$ for 10 minutes. Amplification products were visualized on an ABI-3100 or 3730 capillary system (Applied Biosystems, Inc; http:// www3.appliedbiosystems.com). Peaks were scored using the peak label function in Genotyper (v. 3.7) and GeneMapper (v. 4.0; Applied Biosystems, Inc.) and verified by visual inspection of the raw data. In order to calibrate allele sizes, 127 samples were replicated between laboratories. In addition, amplification and scoring error rates were assessed using replicated templates $(9 \%$ of samples run at USU and $30 \%$ at NFGEL).

Unique multilocus genotypes were identified using the clonal function in GenAlEx (v. 6; Peakal and Smouse 2006) and manual analysis. To determine if the area described as "Pando" is occupied by a single genotype, stems were labeled by multilocus genotype in ArcGIS (v. 9.0; ESRI, http://www.esri.com), and the resulting figure was overlain with the boundary described by Kemperman and Barnes (1976). Once the boundaries of the dominant (largest) clone were defined, the convex hulls extension for ArcView (v. 3.2, ESRI) was employed to estimate the area covered by the clone (Jenness 2007).

\section{Results and Discussion}

Our genetic analyses confirm the existence of "Pando," the highly publicized clone which has been previously described based only on morphological evidence (Grant et al. 1992, Grant 1993, Mitton and Grant 1996). The single genotype representing "Pando" was detected in 141 of the 209 samples. An additional 5 genotypes, each differing from the dominant genotype by a single allele, were also identified. All 5 of these variants were adjacent to one of the sampling points with the dominant genotype. Presuming that these single muta- tional variants are of somatic origin, the genetic boundaries of this clone correspond very closely with the boundaries originally described by Kemperman and Barnes (1976; Fig. 1). Three of the samples differing from the dominant genotype at a single allele were collected as cambium tissue; the remaining cambium samples had genotypes identical to those observed in leaf samples. According to our convex hulls analysis estimates, this clone covers approximately 43.6 ha, almost identical to the 43.3 ha estimated by Kemperman and Barnes (1976).

Surprisingly, an additional 40 genotypes were observed in the remaining 63 samples, which were distributed along the borders of the "Pando" clone. In contrast to the putative somatic variants, these genotypes differed from the dominant genotype at between 4 and 7 alleles. This genotypic diversity was well above our estimated laboratory error rates $(0.000$ and 0.047 mismatches per allele for samples analyzed at USU and NFGEL, respectively; all interlab replicates were concordant). Our sampling strategy did not allow us to define the boundaries of these other genotypes. Additional sampling and further molecular analysis in this stand is underway to determine whether these 40 genotypes are of somatic or sexual origin.

Clones of aspen in the Intermountain West are expected to be large and to span many acres (Barnes 1966, Mitton and Grant 1980). Yet even in context of western aspen, the "Pando" clone is enormous, potentially precluding other clones from sharing the canopy. Such a pattern would contrast to genet distribution in eastern North America, where both stands and genets tend to be small (Wyman et al. 2003, Namroud et al. 2005), and in the Pacific West, where large stands consist of multiple, smaller genets (Hipkins and Kitzmiller 2004).

Despite "Pando's" apparent ecological success, fragmentation of the stand is occurring (personal observation). A lack of vegetative recruitment within the stand is of concern to land managers. The results of clearing mature stems and protecting the area with deer exclosures (Fig. 1) indicate that ungulate browsing is responsible, at least in part, for the lack of recruitment (Kay and Bartos 2000). Anthropogenic activity, including the development of cabins and campgrounds, is also fragmenting the clone. Finally, stems are succumbing to sooty-bark canker (Encoelia pruinosa [Ellis \& 
Everh.] Torkelson \& Eckblad), a fungal infection that typically kills stems within 3-10 years (Johnson et al. 1995). The interaction between these disturbances coupled with the lack of recruitment of new stems may lead to the decline of this clone.

Identification of "Pando's" boundaries using genetic markers provides opportunities for future studies. For example, the recent publication of the Populus trichocarpa Torr. \& A. Gray genome (Tuskan et al. 2006) provides tools for studies of adaptively significant loci in addition to the putatively neutral markers reported here. Previous work has described Populus transcriptomes involved in autumn senescence (Andersson et al. 2004), leaf responses to elevated carbon dioxide (Gupta et al. 2005, Taylor et al. 2005), and abiotic stress including elevated salt concentrations (Brosché et al. 2005). Although greater variation in gene expression is expected among unrelated individuals, variation among closely related or genetically identical individuals has been reported (Whitehead and Crawford 2006) and is often associated with environmental variables affecting fitness (Lexer et al. 2007). Pando presents an excellent opportunity to study variation in gene expression within a single genotype. The large area covered by a single genet may provide microclimate variation and reveal the effect of abiotic factors on development and physiology within a similar genetic background. The southeast mountainside occupied by "Pando" spans nearly $100 \mathrm{~m}$ of elevation, and slopes range from over $30 \%$ (at maximum elevation of $2790 \mathrm{~m}$ ) to $0 \%$ in the seasonal floodplain (minimum elevation 2700 $\mathrm{m})$. Experimental studies within this large clone may provide insights into the interaction among environmental variables and gene expression.

Numerous stems and the large area covered by this single genetic organism make it an excellent subject for studies of somatic mutation rates. Although somatic mutation has been described at microsatellite loci in micropropagated aspen (Rahman and Rajora 2001), estimates of mutation rates across loci, or substitution rates in coding regions, remain undetermined. The longevity of aspen in western landscapes has been partially attributed to the accumulation of beneficial somatic mutations (Tuskan et al. 1996). Additional research, possibly using large clones such as "Pando," into the accumulation and propagation of somatic mutations could be an important step toward understanding phenomena such as clonal growth and senescence (Gardner and Mangel 1997, Eckert 2001, Vaupel et al. 2004).

\section{ACKNOWLEDGMENTS}

We thank Ricardo Hernandez, Kristin Motz, Robert C. Saich, Brian and Anna Cardall, Sean Kelly, Olivia Salmon, and the Mock family (Jon, Jerrell, and Kelton) for assistance with sample collections and in the laboratory. We also thank Bob Campbell and Dale Bartos for their encouragement and support. This study was funded in part by the USDA Forest Service Rocky Mountain Research Station, the Community University Research Initiative, and the Utah State University ADVANCE Program.

\section{Literature Cited}

Andersson, A., J. Keskitalo, A. Sjödin, R. Bhalerao, F. Sterky, K. Wissel, K. Tandre, H. Aspeborg, R. Moyle, Y. Ohmiya, et AL. 2004. A transcriptional timetable of autumn senescence. Genome Biology 5:R24.

BARnEs, B.V. 1966. The clonal growth habit of American aspens. Ecology 47:439-447.

Brosché, M., B. Vinocur, E.R. Alatalo, A. Lamminmäki, T. Teichmann, E.A. Ottow, D. DJilianov, D. Afif, M.B. Bogeat-Triboulot, A. Altman, et al. 2005. Gene expression and metabolite profiling of Populus euphratica growing in the Negev desert. Genome Biology 6:R101.

Di Orio, A.P., R. Callas, and R.J. Schaefer. 2005. Fortyeight year decline and fragmentation of aspen Populus tremuloides in the South Warner Mountains of California. Forest Ecology and Management 206:307313.

Eckert, C.G. 2001. The loss of sex in clonal plants. Evolutionary Ecology 15:501-520.

Gardner, S., and M. Mangel. 1997. When can a clonal organism escape senescence? American Naturalist 150:462-490.

GRant, M. 1993. The trembling giant. Discover 14:83-88.

Grant, M., J.B. Mitton, and Y.B. Linhart. 1992. Even larger organisms. Nature 360:216.

Gupta, P., S. Duplessis, H. White, D.F. Karnosky, F. MarTIN, AND G.K. PODILA. 2005. Gene expression patterns of trembling aspen trees following long-term exposure to interacting elevated $\mathrm{CO}_{2}$ and tropospheric $\mathrm{O}_{3}$. New Phytologist 167:129-142.

Hipkins, V.D., AND J.H. KitZMiller. 2004. Genetic variation and clonal distribution of quaking aspen in the central Sierra Nevada. Transactions of the Western Section of the Wildlife Society 40:32-44.

Jenness, J. 2007. Convex hulls around points (conv_hulls pots.avx) extension for ArcView 3.x, v. 1.23. Jenness Enterprises. Available from: http://www.jennessent .com/arcview/convex_hulls.htm

Johnson D.W., J.S. BEATTY, AND T.E. Hinds. 1995. Cankers on western quaking aspen. Forest Insect and Disease 
Leaflet 152. USDA Forest Service, Northern Area State and Private Forestry, Radnor, PA.

KAY, C.E., AND D.L. BARTOS. 2000. Ungulate herbivory on Utah aspen: assessment of long-term exclosures. Journal of Range Management 53:145-153.

Kemperman, J.A., and B.V. Barnes. 1976. Clone size in American aspens. Canadian Journal of Botany 54: 2603-2607.

LeXer, C., M. Van LoO, and T. Barbará. 2007. Towards forest community and ecosystem genomics. New Phytologist 173:673-676.

LitTLE, E.L., JR. 1971. Atlas of United States trees. Volume 1, Conifers and important hardwoods. USDA Forest Service Miscellaneous Publication 1146, Washington, DC.

MitTon, J.B., AND M.C. GRANT. 1980. Observations on the ecology and evolution of quaking aspen, Populus tremuloides, in the Colorado Front Range. American Journal of Botany 67:202-209.

1996. Genetic variation and the natural history of quaking aspen. BioScience 46:25-31.

Namroud, M.-C., A. Park, F. Tremblay, and Y. Bergeron. 2005. Clonal and spatial genetic structures of aspen Populus tremuloides Michx. Molecular Ecology 14: 2969-2980.

Peakal, R., and P.E. Smouse. 2006. GENALEX 6: genetic analysis in Excell. Population genetic software for teaching and research. Molecular Ecology Notes 6:288-295.

Rahman, M.H., AND O.P. Rajora. 2001. Microsatellite DNA somaclonal variation in micropropagated trembling aspen Populus tremuloides. Plant Cell Reports 20: $531-536$

Romme, W.H. 1982. Fire and landscape diversity in subalpine forests of Yellowstone National Park, Wyoming, USA. Ecological Monographs 52:199-221.

Romme, W.H., and D.G. Despain. 1989. Historical perspective on the Yellowstone USA fires of 1988. BioScience 39:695-699.
Taylor, G., N.R. Street, P.J. Tricker, A. Sjödin, L. Graham, O. Skogström, C. Calfapietra, G. ScarasciaMugnOZZA, AND S. Jansson. 2005. The transcriptome of Populus in elevated $\mathrm{CO}_{2}$. New Phytologist 167: 143-154.

Tuskan, G.A., S. Difazio, S. Jansson, J. Bohlmann, I. Grigoriev, U. Hellsten, N. Putnam, S. Ralph, S. Rombauts, A. Salamov, ET aL. 2006. The genome of black cottonwood, Populus trichocarpa Torr. \& A. Gray. Science 313:1596-1604.

Tuskan, G.A., K.E. Francis, S.L. Russ, W.H. Romme, and M.G. TURNER. 1996. RAPD markers reveal diversity within and among clonal and seedling stands of aspen in Yellowstone National Park, U.S.A. Canadian Journal of Forest Research 26:2088-2098.

VAN DER SCHOOT, J., M. Pospiskova, B. VOSMAN, and M.J.M. SMULDERS. 2000. Development and characterization of microsatellite markers in black poplar (Populus nigra L.). Theoretical and Applied Genetics 101(1-2): 317-322.

Vaupel, J.W., A. Baudisch, M. Dolling, D.A. Roach, AND J. Gampe. 2004. The case for negative senescence. Theoretical Population Biology 65:339-351.

Whitehead, A., and D.L. Crawford. 2006. Variation within and among species in gene expression: raw material for evolution. Molecular Ecology 15:11971211.

Wyman, J., A. Bruneau, and M.-F. Tremblay. 2003. Microsatellite analysis of genetic diversity in four populations of Populus tremuloides in Quebec. Canadian Journal of Botany 81:360-367.

Received 28 August 2007 Accepted 4 June 2008 